Relations industrielles

Industrial Relations

\title{
Semaine sociale de France
}

Volume 8, numéro 3, juin 1953

URI : https://id.erudit.org/iderudit/1024036ar

DOI : https://doi.org/10.7202/1024036ar

Aller au sommaire du numéro

\section{Éditeur(s)}

Département des relations industrielles de l’Université Laval

\section{ISSN}

0034-379X (imprimé)

1703-8138 (numérique)

Découvrir la revue

Citer cet article

(1953). Semaine sociale de France. Relations industrielles / Industrial Relations, 8(3), 339-339. https://doi.org/10.7202/1024036ar

Tous droits réservés @ Département des relations industrielles de l’Université Laval, 1953
Ce document est protégé par la loi sur le droit d'auteur. L’utilisation des services d'Érudit (y compris la reproduction) est assujettie à sa politique d'utilisation que vous pouvez consulter en ligne.

https://apropos.erudit.org/fr/usagers/politique-dutilisation/ 


\section{SEMAINE SOCIALE DE FRANCE}

Les Semaines Sociales de France tiendront, cette année, à Pau, du 20 au 26 juillet, leur quarantième Session, qui correspond à leur quarante-neuvième anniversaire.

Elles n'ont pas reculé devant un sujet brûlant, difficile et périlleux: GUERRE et PAIX, avec ce sous-titre: de la coexistence des blocs à une Communauté internationale. C'est d'ailleurs la suite normale et attendue de la Semaine Sociale sur la Communauté Nationale, tenue à Strasbourg en 1946, au lendemain de la guerre.

Les Semaines Sociales ont senti et compris toutes les difficultés de la tâche. Elles ont pensé que leur devoir, que leur mission intellectuelle et spirituelle les contraignaient à affronter et, dans toute la mesure du possible, à surmonter les obstacles.

Leur but n'est pas de donner une réponse définitive à tous les cas que peuvent se poser les consciences individuelles.

La Semaine Sociale de Pau se propose trois buts:

1-Repérer, situer, analyser et expliquer les faits contemporains, en ce qui concerne la guerre et la paix, de la façon la plus consciencieuse et la plus scientifique;

2-Rappeler les principes moraux qui gouvernent l'action internationale des chrétiens en les appliquant aux faits d'aujourd'hui;

3--Dégager des orientations assez précises pour dépasser le domaine des généralités inefficaces, assez larges pour laisser tout le jeu aux libertés que les personnes et les divers groupes tiennent de leurs responsabilités.

Ce travail sera fait à la lumière de l'Evangile, à la lumière aussi de l'enseignement des Papes et, en particulier, de S.S. Pie XII, par des spécialistes des sciences de l'homme confrontant leurs connaissances et leurs points de vue, selon la méthode habituelle des Semaines Sociales.

Un dépliant-programme peut être obtenu en s'adressant au Secrétariat permanent des Semaines Sociales de France, 16, rue du Plat, Lyon $2^{\circ}$, France. 